[Denpun Kagaku, Vol. 36, No. 4, p. 311 323 (1989)]

Award Address

\title{
Some Aspects of the Structure of Starch and Glycogen
}

\author{
David J. MANNERS* \\ Department of Biological Sciences, Heriot-Watt University \\ (Edinburgh EH14 4AS, Scotland)
}

\section{INTRODUCTION}

In many scientific careers, certain years have a special significance. For the writer, 1949 and 1989 are such years. In 1949, I began my research career in Cambridge, by studying the structure of glycogen, under the direction of the late Dr. D. J. Bell, who since 1934 had published a series of papers on this subject." ${ }^{1)}$ At this time, periodate oxidation methods of analysis and paper chromatography were being developed, and these techniques were amongst those widely used in these and later studies. The research also involved an examination of a series of dextrins prepared for me, by an amylolytic degradation of rabbit liver glycogen. One of these, a " $\beta$-dextrin," had an apparent chain length of nine glucose residues, compared to 12 for the original glycogen, suggesting that on the average, three glucose residues were removed by $\beta$-amylase from each chain. However, the " $\beta$-dextrin" was, in fact, further degraded by crystalline $\beta$-amylase, and the true $\beta$-limit dextrin had a chain length of seven. Although this observation was a disappointment at that time, it led to a lasting understanding of the importance of enzyme and substrate concentrations, which was invaluable over the next four decades. The researches on glycogen also involved classical methylations by the Haworth and Purdie procedures, followed by chromatographic separations of the methylated sugars. From this work came an awareness of the great debt that is owed to the pioneers of polysaccharide chemistry for their painstaking

* Address for correspondence : 165 Mayfield Road, Edinburgh EH 93 AY, Scotland. efforts in the $1930 \mathrm{~s}$ and $1940 \mathrm{~s}^{2-4)}$ This fact tends to be overlooked by many who use modern facile and rapid methods of analysis.

In 1989, our researches on starch and glycogen have been greatly honoured by this Society. In this review, a selection of this work will be described in four sections. The first covers a period in the 1950s and 1960s when it seemed probable that both polysaccharides contained a small proportion of $(1 \rightarrow 3)-\alpha$-D-glucosidic linkages. This would have important implications with respect to the biosynthesis and degradation of these two $\alpha$-D-glucans. Fortunately, but with one possible exception, the proposition appears to be untrue. However, there is no guarantee that newly discovered samples of starch and glycogen from unusual biological sources such as uncommon algae and protozoa will not contain some anomalous linkages. The second section describes briefly the detection of anomalous linkages in amylose, and their identification by enzymic rather than chemical methods. The key to this work was yeast isoamylase, a debranching enzyme first described by Japanese biochemists. ${ }^{5,6}$ Debranching enzymes also play a major part in the third section which describes studies on the degree of multiple branching in amylopectin and glycogen. Multiple branching originally described the presence of chains containing more than one branch point as an integral part of the molecular structure. This was later described in terms of the ratio of A-chains to B-chains. This ratio is an important parameter which relates to the actual molecular models for amylopectin and glycogen. This topic forms the final part of this review. 
Table 1. Evidence of $(1 \rightarrow 3)$-linkages in glycogen and amylopectin.

\begin{tabular}{|c|c|c|}
\hline Polysaccharide & Evidence & Reference \\
\hline \multirow[t]{3}{*}{ Glycogen } & Methylation analysis & Bell $^{7)}$ \\
\hline & $1 \%$ of periodate-resistant residues & Abdel-Akher et al. $\left.{ }^{8}\right)$ \\
\hline & $0.001 \%$ of nigerose in partial acid hydrolysates $\left.{ }^{a}\right)$ & Wolfrom and Thompson ${ }^{9)}$ \\
\hline \multirow[t]{2}{*}{ Amylopectin } & $\begin{array}{l}0.5 \% \text { of periodate-resistant residues in waxy corn } \\
\text { starch }\end{array}$ & Abdel-Akher et $a l^{8)}$ \\
\hline & $0.13 \%$ of nigerose in partial acid hydrolysates $\left.{ }^{a}\right)$ & Wolfrom and Thompson ${ }^{10)}$ \\
\hline \multirow[t]{2}{*}{ Floridean Starch } & $0.28 \%$ of nigerose in partial acid hydrolysates & Peat et al. ${ }^{23)}$ \\
\hline & Traces of nigerose in partial enzymic hydrolysates & Peat et al. ${ }^{24)}$ \\
\hline
\end{tabular}

a) Isolated as twice this weight of octa-acetate.

\section{OBSERVATIONS ON THE POSSIBLE PRESENCE OF $(1 \rightarrow 3)$-LINKAGES IN AMYLOPECTIN AND GLYCOGEN}

Although it has been accepted for many years that the molecular structures of amylopectin and glycogen can be described in terms of $(1 \rightarrow 4)$ $\alpha$-D-glucosidic inter-residue linkages and $(1 \rightarrow 6)$ $\alpha$-D-glucosidic inter-chain linkages, in the early stages of our research, there were several reports of the presence of $(1 \rightarrow 3)$-glucosidic linkages in these glucans. These are summarised in Table 1.

The methylation analysis of amylopectin and glycogen was always difficult, and complicated by the need to ensure that the methylation was complete (the theoretical methoxyl content of 45. $6 \%$ was rarely achieved), and that hydrolytic demethylation of $2: 3: 6$-tri- $O$-methyl D-glucose was minimised. Both factors could lead to the formation of di-O-methyl D-glucose which did not originate from triply-linked branch point residues. In studies of both rabbit liver and rabbit muscle glycogen, Bell reported $^{\text {7) }}$ that $2: 6$-di- $O$-methyl D-glucose was the predominant di-O-methyl sugar. With certain reservations, this was viewed as evidence for the presence of $(1 \rightarrow 3)$-linkages. Many years later, ${ }^{11}$ a methylation study of glycogen and amylopectin polyalcohols gave a negligible amount of $2: 6$ di-O-methyl D-glucose.

During the 1950s, periodate oxidation methods of analysis were being developed in several laboratories, particularly those of E. L. Hirst (later Sir Edmund Hirst) and F. Smith. The latter showed that periodate oxidised polysaccharides (polyaldehydes) could be reduced with borohydride to the corresponding polyalcohols, and that total or partial acid hydrolysis of the polyalcohols could give valuable structural information. $^{8)}$ Non-reducing end-groups were released as glycerol, $(1 \rightarrow 4)$-linked D-glucose residues were converted into erythritol, and periodate-resistant residues appeared as D-glucose. They reported ${ }^{8)}$ that glycogen and amylopectin contained about 1.0 and $0.5 \%$ of periodateresistant residues which could either be $(1 \rightarrow 3)$ linked or arise from an inter-chain linkage at $\mathrm{C} 2$ or $\mathrm{C} 3$. In further experiments, waxy corn starch gave 0.2 to $0.5 \%$ of glucose, and the $\beta$ limit dextrin $0.33 \%$ of glucose. ${ }^{12)}$ With glycogen from crappie fish liver and rat liver, the polyalcohols contained 0.86 and $0.74 \%$ of glucose respectively, corresponding to one periodate resistant residue in about $130-150$ glucose residues $^{13)}$. The possibility that this glucose could arise from incomplete oxidation of the glucans was recognised by the authors. Our own work $^{14)}$ indicated that this was, in fact, the most probable source of the glucose. Samples of waxy maize and waxy sorghum starches and potato amylopectin were oxidised with periodate for 14 days at $20-26^{\circ} \mathrm{C}$, reduced to the corresponding polyalcohol, and hydrolysed with acid. Significant amounts of glucose could not be detected in the hydrolysates. Control experiments with lichenin showed that $(1 \rightarrow 3)$-linkages were not hydrolysed by the acid formed during the prolonged periodate oxidation. The overall results supported our earlier studies ${ }^{15)}$ on glycogen polyaldehydes, which on acid hydrolysis, 
also did not yield significant amounts of glucose.

The third line of evidence for $(1 \rightarrow 3)$-linkages arose from the isolation of small amounts of nigerose from partial acid hydrolysates of starchtype polysaccharides (Table 1 ). The hydrolyses were carried out under conditions in which the formation of oligosaccharides by acid reversion from glucose was minimised. ${ }^{16)}$ Wolfrom and Thompson ${ }^{9,10)}$ concluded that a small number of $(1 \rightarrow 3)-\alpha$-D-glucosidic linkages were present in both amylopectin and glycogen. It seemed to $\mathrm{us}^{17)}$ that the relatively small amounts of nigerose could arise by acid-catalysed transglucosidation from maltose. In control experiments, dilute solutions (0.4-1.0\%) of maltose were heated with mineral acid. Significant quantities of both isomaltose and nigerose were produced, but $\beta$-linked disaccharides as formed by acid reversicn ${ }^{16)}$ were absent. Moreover, when amylopectin was hydrolysed in the presence of ${ }^{14} \mathrm{C}$ glucose, a mixture of radio-active oligosaccharides was produced with the paper chromatographic properties of maltose, isomaltose and nigerose. ${ }^{17)}$ We therefore concluded that the presence of very small amounts of nigerose in partial acid hydrolysates of glycogen and amylopectin could not be used as unequivocal evidence for the presence of $(1 \rightarrow 3)-\alpha$-D-glucosidic linkages.

This phase of our research work covered some 15 years or so, and confirmed the relative chemical simplicity of amylopectin and glycogen in terms of only $(1 \rightarrow 4)$ - and $(1 \rightarrow 6)$ - $\alpha$-D-glucosidic linkages. As we shall see later, this apparent simplicity is deceptive! For example, the partial acid hydrolysis of glycogen led to the isolation of isomaltotriose (about $250 \mathrm{mg}$ ) from $92 \mathrm{~g}$ of cow liver glycogen." This yield could be significant, and implies that in the molecule there are adjacent $(1 \rightarrow 6)-\alpha$-linked $\mathrm{D}$ glucose residues $i . e$, regions with an abnormally high degree of branching. Hence, the branch points are irregularly dispersed within the macromolecule.

During the 1950s, investigations of Floridean starch, the reserve carbohydrate of the red alga Dilsea edulis proved to be perplexing. In 1949, Floridean starch was shown ${ }^{18}$ to differ from normal starches in reducing only $0.6 \mathrm{~mol}$ of periodate per glucose residue (normal values were $1.05-1.10 \mathrm{~mol}$ ) and in being resistant to crystalline $\beta$-amylase. The presence of a proportion of $(1 \rightarrow 3)$-linked glucose residues was postulated. However, a later re-examination of the same sample gave ${ }^{19)}$ a periodate reduction of $1.05 \mathrm{~mol}$ and a $\beta$-amylolysis limit of $46 \%$. Other samples of Floridean starch were also partly degraded by $\beta$-amylase and potato phosphorylase, whilst yeast isoamylase caused a $10-20 \%$ increase in $\beta$-amylolysis limit. ${ }^{19)}$ In various laboratories, measurement of the average chain length by periodate oxidation gave a range of results from nine to $18 .^{20}$ A chain length of 15 has been obtained by enzymic analysis. ${ }^{21)}$ The overall results indicated a structure intermediate between glycogen and amylopectin, although in terms of physical properties, the Floridean starch was amylopectin in type. ${ }^{22)}$

A partial acid hydrolysis study gave a small but possibly significant yield of nigerose $(35 \mathrm{mg}$ from $12.5 \mathrm{~g}$ starch). ${ }^{23}$ Trisaccharide fragments on partial hydrolysis also gave some nigerose. Moreover, on $\beta$-amylolysis, traces of nigerose were detected, ${ }^{24)}$ and on sequential degradation with $\alpha$-amylase, R-enzyme (a debranching enzyme from broad beans), and $\alpha$-amylase, nigerose was again detected. ${ }^{24}$ ) It therefore seems possible that Floridean starch does contain a small proportion of $(1 \rightarrow 3)$-linked $\alpha$-D-glucose residues, but their location within the macromolecule has not yet been established. Whether Floridean starch from other Rhodophyceae also contain these linkages has not been determined.

\section{THE FINE STRUCTURE OF AMYLOSE}

Whilst the presence of anomalous linkages in amylopectin and glycogen could not be confirmed, the possible presence of such linkages in amylose provided a most intriguing story. The incomplete degradation of amylose by crystalline $\beta$-amylase was first shown by Peat and his coworkers, ${ }^{25)}$ who reported $\beta$-amylolysis limits of only $68-70 \%$ for various samples of amylose. These results were not due to contamination of the amylose with amylopectin, and were later confirmed in several other laboratories, including our own. ${ }^{26)}$ However, amorphous preparations of $\beta$-amylase caused 
the complete degradation of the same samples of amylose, due to the presence of a second carbohydrase, termed Z-enzyme. In 1952, it was believed that $Z$-enzyme exerted a debranching action on amylose, and since $Z$ enzyme preparations also showed $\beta$-glucosidase activity, it was suggested ${ }^{27}$ ) that the barriers to $\beta$-amylase were single glucose residues attached by $\beta$-glucosidic linkages to a main amylose chain. Later work ${ }^{28,29)}$ showed that the $Z$ enzyme activity was, in fact, due to a trace of $\alpha$-amylase in the amorphous $\beta$-amylase preparation, and involved the random hydrolysis of a very small number of $(1 \rightarrow 4)-\alpha$-D-glucosidic linkages. The barriers to $\beta$-amylase in amylose were therefore by-passed by "Z-enzyme" and were not selectively hydrolysed as originally believed.

An additional complication in these studies was the finding of Gilbert and his coworkers ${ }^{30}$ that oxygen treatment of amylose could introduce barriers to phosphorolysis. It was therefore necessary to prepare amylose under anaerobic conditions to avoid any inadvertent modification.

The nature of the barrier to $\beta$-amylase was the subject of much speculation. The possibilities included (a) an anomalous inter-residue linkage, (b) a branch point, (c) an ester phosphate group. However, treatment of amylose with bone phosphatase or acid phosphatase of low specificity did not increase the $\beta$-amylolysis limit ${ }^{27,31)}$

We examined ${ }^{32)}$ the possibility that the anomalous linkages were $(1 \rightarrow 6)-\alpha$-D-glucosidic inter-chain linkages of the type present in amylopectin i.e., that amylose had a very low degree of branching.

At this time, two specific debranching enzymes were known which could hydrolyse the outermost inter-chain linkages in amylopectin. One of these, from broad beans and other higher plants, was termed R-enzyme, ${ }^{33)}$ but was difficult to prepare entirely free of $\alpha$-amylase. The other, from yeast, was termed isoamylase by Maruo and Kobayashi, ${ }^{6)}$ and the specificity was known in some detail. ${ }^{34}$ Incubation of various samples of potato amylose with yeast isoamylase resulted in small but significant increases in $\beta$-amylolysis limit (5-12
$\%$ ) which were accompanied by limited decreases in specific viscosity $(12-20 \%)$. This is evidence that debranching had occurred. A sample of amylose $\beta$-limit dextrin showed a substantial increase in $\beta$-amylolysis limit $(70 \%$, equivalent to $95 \%$ degradation of the original amylose), without any change in specific viscosity, confirming the absence of $\alpha$-amylase from the yeast isoamylase. In some experiments, the total degradation of amylose was about 90 $\%$. The residual $10 \%$ could be accounted for by some retrogradation of amylose during enzymic digestion, and the relatively low specific activity of the isoamylase, then prepared without the benefit of modern chromatographic procedures. Nevertheless, the overall results provided evidence that the amylose samples had a low degree of branching, and contained a very small number of branch points per molecule. This conclusion has been confirmed by other workers using bacterial pullulanase ${ }^{35)}$ or isoamylase $^{36)}$ to debranch the amylose.

The small proportion of branch points in amylose was too low to be detected by the chemical techniques then available. However, a methylation study of amylose polyalcohol later ${ }^{37)}$ provided evidence of $(1 \rightarrow 6)$ branch points by the isolation of very small amounts of 1-O-methylerythritol. With maize and potato amylose, the proportion of $(1 \rightarrow 6)$-linkages was 1 in 300 and 1 in 400 respectively, and there were probably two or three branch points per molecule.

Our related studies on amylose had previously shown ${ }^{26)}$ that laboratory prepared specimens were heterogeneous, and contained a mixture of molecules of varying molecular weight and $\beta$-amylolysis limit. With potato amylose, the smallest molecules had a degree of polymerisation, (d. p.) of about 1800 , and were entirely linear. The larger molecules had a d.p. of $5000-6000$ and a $\beta$-amylolysis limit of $50-60 \%$. This means that in the biosynthesis of amylose, only a proportion of the molecules are transient substrates for Q-enzyme. The factors which control the concomitant synthesis of amylose and amylopectin within a single starch granule remain to be elucidated.

Our original experiments ${ }^{32)}$ on potato amylose were followed by others on amyloses isolated 
from various cereal, algal and protozoal starches. $^{38)}$ In all cases, yeast isoamylase caused a significant increase in $\beta$-amylolysis limit, indicating that a very low degree of branching was a general feature of amylose. This conclusion has been confirmed by others, particularly Banks and Greenwood, ${ }^{35)}$ who examined amyloses from 17 different starches, and Hizukuri and his coworkers, who have studied a wide range of starches inciuding several varieties of rice. ${ }^{39}$ )

The structural analysis of amylose has been greatly improved by Hizukuri and his coworkers $^{40)}$ who have devised methods for the determination of the $d$. p. and average chain length (c. 1.) of amyloses. Their results ${ }^{39,40)}$ have now given quantitative information on the average number of branch points in amylose molecules from many starches, and the proportion of linear and branched molecules.

Our overall studies on amylose occupied more than a decade, and provided a good example of the use of enzymic methods for the investigation of the fine structure of a starch-type polysaccharide. This brief review cannot, however, do full justice to the intense interest that was aroused by the original observations of Peat and his coworkers, ${ }^{25,27)}$ and the subsequent speculation on the nature of $\mathrm{Z}$-enzyme and the anomalous linkages in amylose.

\section{MULTIPLE BRANCHING IN AMYLOPECTIN AND GLYCOGEN}

In 1952 , a very significant paper was published by Peat and his coworkers. ${ }^{41}$ They defined three types of chain in amylopectin. A-chains were linked to the molecule only by the potential reducing group; B-chains carried one or more other chains, and were also linked by the potential reducing group to the rest of the molecule; the C-chain was terminated by the sole reducing group (Fig. 1). There was only one $\mathrm{C}$-chain per molecule and for many purposes, it could be regarded as a B-chain. Peat and his coworkers ${ }^{41}$ developed an enzymic method for the detection of A-chains, and hence, measurement of the ratio of A-chains to B-chains, which is a measure of the degree of multiple branching in the molecule.
The experimental method involved preparation of the $\beta$-dextrin of amylopectin which was then debranched with R-enzyme. ${ }^{41}$ The products were maltose and maltotriose arising from the A-chains, and maltohexaose and higher maltosaccharides from the B-chains. The yield of maltose and maltotriose gave the proportion of A-chains. In this first experiment, the yield was initially given as $5.3 \%$, and later ${ }^{42)}$ corrected to $12.8 \%$. This result enabled a decision to be made between three possible models for amylopectin as proposed by Haworth, Staudinger and Meyer (Fig. 1). Assuming that the $\beta$-dextrin had a d.p. of 3000 , the yield of maltose and maltotriose from a Haworth structure would be $0.083 \%$, and from a Staudinger structure (in which all the chains except one were A-chains) would be about $25 \%$. The experimental result thus favoured the Meyer-type structure with multiple and random branching.

From this single experiment, a whole chapter of starch biochemistry has followed. Although the concept was outstanding, and the experimental design was relatively simple, the operation was more complex. Firstly, the $\beta$-dextrin had to be free of any maltose released during the initial $\beta$-amylolysis, and the molar ratio of maltose : maltotriose should be $1: 1$. In the original experiment this molar ratio was actually $1.45: 1$, and could be explained by $1.9 \%$ of the maltose from the $\beta$-amylolysis being retained in the $\beta$-dextrin sample. ${ }^{41}$ The sample of waxy maize starch used had a c. 1. of 24.4 and $\beta$-amylolysis limit $52 \%$. A Meyer model with equal numbers of $\mathrm{A}$ - and B-chains would yield $10.4 \%$ of maltose and maltotriose. The observed yield of $12.8 \%$ is equivalent to an $\mathrm{A}: \mathrm{B}$ ratio of $1.5: 1$. However, if the molar ratio of maltose : maltotriose was actually $1: 1$, the calculated yield of maltose and maltotriose decreased to $10.7 \%,{ }^{43)}$ which is very close to that of the ideal Meyer model. It is therefore essential that the $\beta$-dextrin is free of maltose, if the calculated $\mathrm{A}: \mathrm{B}$ chain ratios are to be significant.

In a refinement of the method, Enevoldsen and Juliano ${ }^{43}$ have measured the yield of maltotriose released from amylopectin $\beta$-dextrin by (a) a debranching enzyme, (b) a mixture of $\beta$-amylase and debranching enzyme. The 


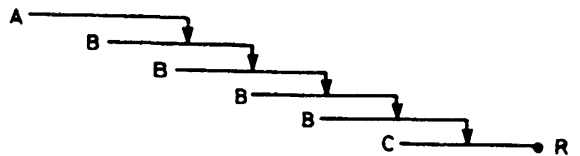

(a) Haworth structure

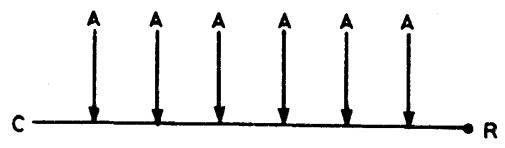

(b) Staudinger structure

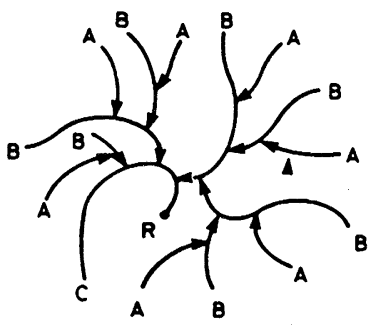

(c) Meyer structure

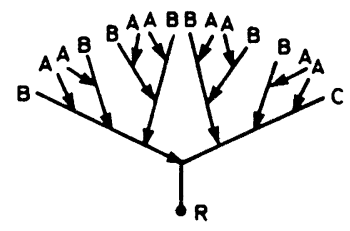

(d) Redrawn Meyer structure

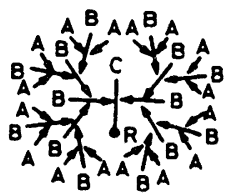

(e) Revised Meyer structure

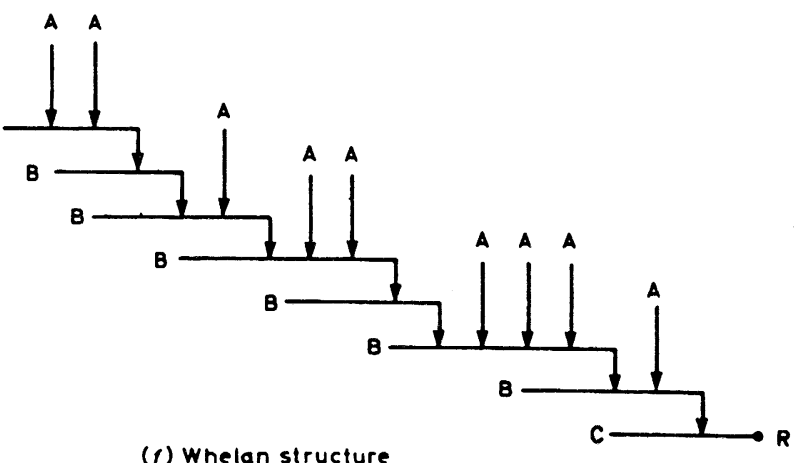

Fig. 1. Diagrams of the molecular structures of amylopectin and glycogen, as proposed by (a) Haworth ; (b) Staudinger ; (c) Meyer $\left.{ }^{53}, 57\right)$; (d) the Meyer structure redrawn as a regularly branched structure ${ }^{63)}$; (e) the Whelan revision ${ }^{66}$ of the Meyer structure; (f) the Whelan elongated structure. ${ }^{52)}$ From Manners, ${ }^{59)}$ reproduced by permission of Cereal Foods World.

former yield $(p)$ arises from one half of the A-chains, and the latter yield $(q)$ arises from one half of the total A and B-chains; the A : $\mathrm{B}$ ratio is then given by $\frac{p}{q-p}$. This modification circumvents the problem of contamination of the $\beta$-dextrin with maltose.

Secondly, the purity of the $\beta$-amylase and debranching enzyme must be established. Many $\beta$-amylase preparations contain traces of $\alpha$ glucosidase which must be eliminated to prevent the loss of maltose and the formation of glucose. The plant R-enzyme as originally used was difficult to prepare completely free from $\alpha$-amylase, and had no action on glycogen. For these reasons, bacterial pullulanase which debranches both glycogen and amylopectin $\beta$ dextrins and can be readily prepared (it is now commercially available), has been used in later studies.

Thirdly, the separation of the maltose and maltotriose was originally carried out by charcoal-Celite chromatography and required $\mathrm{g}$. quantities of $\beta$-dextrin. ${ }^{41,42)}$ With the development of gel filtration and HPLC methods for the separation of oligosaccharides, the analysis can now be carried out on the mg scale. ${ }^{43)}$

Following the original work of Peat and his coworkers, ${ }^{31,42)}$ we determined the ratio of $\mathrm{A}$ : $\mathrm{B}$ chains in potato amylopectin and waxy sorghum starch using pullulanase as the debranching enzyme. The results indicated ratios of $1.3: 1$ and $1.2: 1$, respectively. ${ }^{45}$ ) Workers in other laboratories have reported generally similar results for a wide variety of amylopectins; in most samples, there are rather more 
Table 2. Properties of some glycogens and amylopectins.a)

\begin{tabular}{lccccc}
\hline Sample & c. 1. & $\begin{array}{c}\beta-A m y l o l y s i s \\
\text { limit }(\%)\end{array}$ & ECL & ICL & A : B ratio \\
\hline Glycogens & & & & & \\
$\quad$ Ascaris lumbricoides & 12 & 49 & 8 & 3 & $0.6: 1$ \\
Human liver & 15 & 46 & 9 & 5 & $0.8: 1$ \\
Mytilus edulis & 13 & 46 & 8 & 4 & $0.9: 1$ \\
Oyster & 10 & 40 & 6 & 3 & $0.7: 1$ \\
Pig liver & 15 & 50 & $9-10$ & $4-5$ & $1.1: 1$ \\
Rabbit liver & 13 & 50 & $8-9$ & $3-4$ & $0.7: 1$ \\
\hline Amylopectins & & & & & \\
Potato amylopectin & 24 & 55 & 15 & 8 & $1.3: 1$ \\
Waxy sorghum & 24 & 58 & 16 & 7 & $1.2: 1$ \\
Waxy maize & 20 & 50 & 12 & 7 & $1.0: 1$ \\
\hline
\end{tabular}

a) Based on Refs. 45 and 47.

b) ECL, exterior chain length i.e., no. of glucose residues removed by $\beta$-amylase plus 2.0. ICL, interior chain length given by $\mathrm{ICL}=\mathrm{c} .1 .-\mathrm{ECL}-1$.

A-chains than B-chains, the ratios varying from about $1.0: 1$ to $1.5: 1 .^{38,44)}$

In 1974, an alternative method of analysis was described, ${ }^{46)}$ which was based on a comparison of the reducing power produced when a $\beta$-dextrin was digested with either isoamylase or a mixture of isoamylase and pullulanase. The former was related to all the B-chains and one half of the A-chains, and the latter to the sum of all the $\mathrm{A}$ and $\mathrm{B}$-chains. The results indicated a range of $\mathrm{A}: \mathrm{B}$ chain ratios from 1.5:1 for wheat and rice amylopectin, to $2.6: 1$ for waxy maize and waxy sorghum starch. Any A : B chain ratio of $2: 1$ or more would have significant implications for any molecular model for amylopectin. However, the method is subject to several limitations which lead to erroneously high $\mathrm{A}: \mathrm{B}$ chain ratios. ${ }^{47,48)}$

Although the determination of the $\mathrm{A}: \mathrm{B}$ chain ratio in amylopectin has been studied in several laboratories (for reviews see Refs. 38, 48 ), the corresponding ratio for glycogen has attracted less attention. In 1966, we examined ${ }^{45)}$ several samples of glycogen, using pullulanase to debranch the $\beta$-dextrins, and found a range of A : B chain ratios of $0.6: 1$ to $1.1: 1$ (Table 2). Marshall and Whelan ${ }^{46)}$ using their method reported a range of values for glycogens from $0.6: 1$ to $1.2: 1$, which was significantly differ- ent from the values for amylopectin (1.5:1 to $2.6: 1)$. The use of a modified MarshallWhelan method gave A : B chain ratios of 0.6 : 1 and 0.8:1 for Helix pomatia and rabbit liver glycogens. ${ }^{47)}$ More recently, Umeki and Yamamoto $^{49}$ have reported ratios of $0.67: 1$ for shellfish glycogen and 1. $3: 1$ for glutinous rice starch $\beta$-dextrin. Their analysis was complicated by the fact that with glycogen, some maltotriose was believed to arise from B-chains, implying a very high degree of branching in some regions of the macromolecules. Confirmation of this suggestion is required.

For many years, we have been trying to establish whether or not amylopectin and glycogen differed significantly in degree of multiple branching. In 1966, the available evidence suggested $^{45)}$ there was no significant difference. By 1989, this opinion has changed. In most glycogens, there appear to be more B-chains than A-chains, whereas with amylopectins, the reverse is true. This difference has implications with respect to the actual molecular models for the two types of polysaccharide.

\section{MOLECULAR MODELS FOR AMYLOPECTIN AND GLYCOGEN}

During the past 50 years or so, many molecular models have been postulated for amylo- 
(a) French "cluster" model

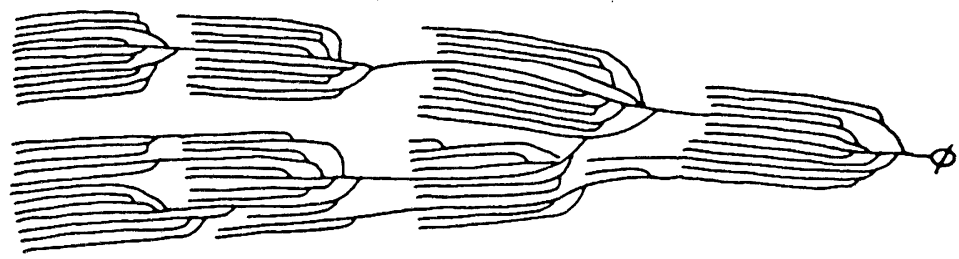

(b) Robin "cluster" model

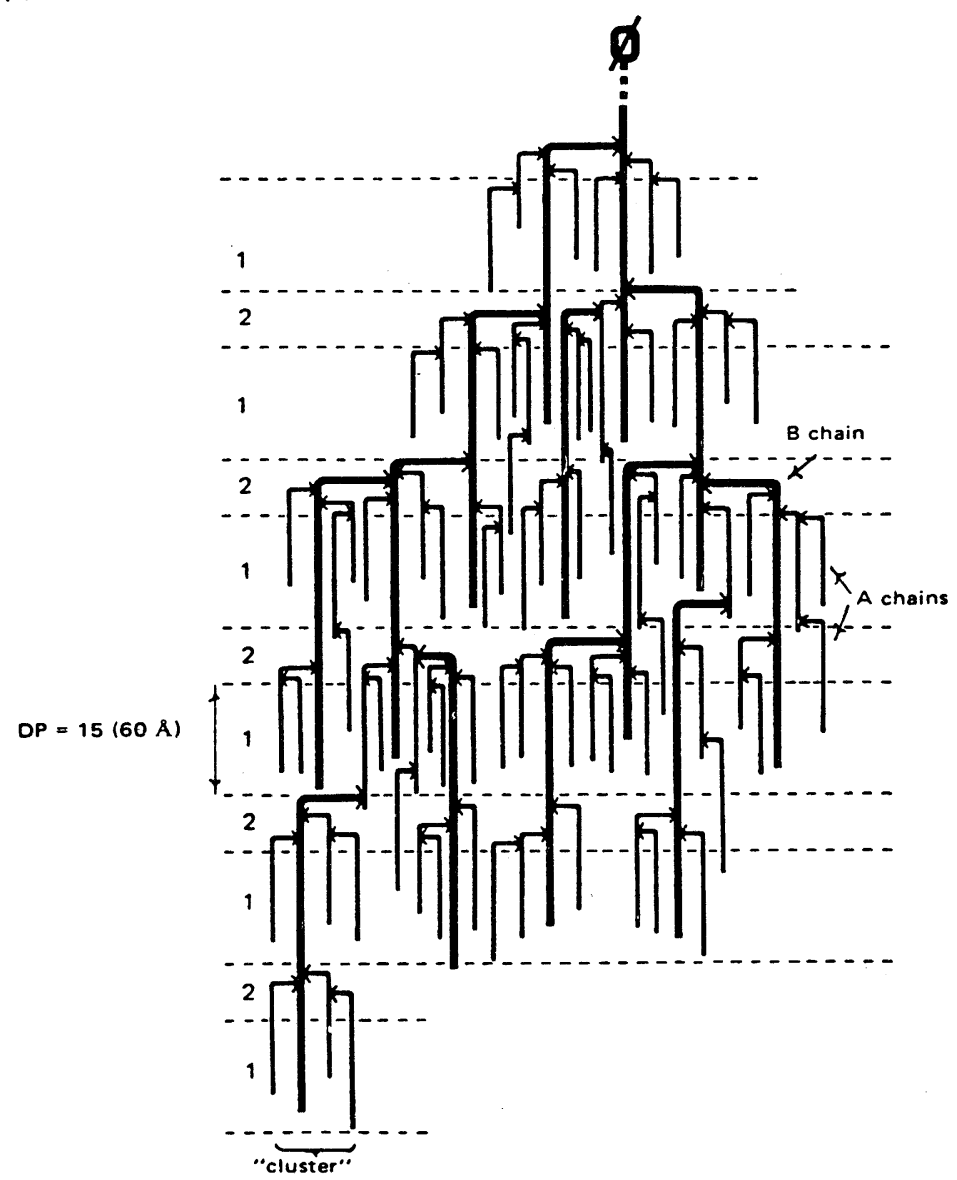

(c) Manners and Matheson "cluster" model

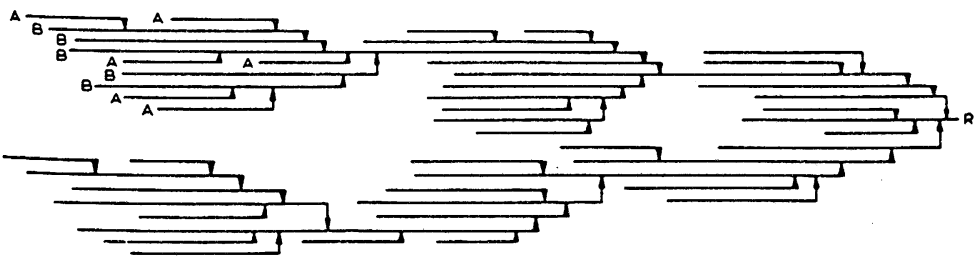

Fig. 2. Structural cluster-type models for amylopectin as proposed by (a) French ${ }^{55)}$; (b) Robin and coworkers ${ }^{56)}$; (c) Manners and Matheson. ${ }^{47)}$ From Manners, ${ }^{59)}$ reproduced by permission of Cereal Foods World. 
pectin and glycogen. Some models were considered to apply equally well to amylopectin and glycogen $e . g$., the 1937 models of Haworth and Staudinger, the 1952 model of Larner and coworkers $^{50}$ and those postulated by Whelan and coworkers in $1970^{51)}$ and $1979 .{ }^{52)}$ Other models were restricted either to amylopectin e. g., those proposed by Meyer and Bernfeld, ${ }^{53)}$ Nikuni, ${ }^{54)}$ French, ${ }^{55)}$ Robin and coworkers ${ }^{56)}$ and ourselves, ${ }^{47)}$ or to glycogen e.g., Meyer and Fuld, ${ }^{57)}$ Goldsmith and coworkers. ${ }^{58)}$ The literature on this subject is now very extensive. Since the molecular models for amylopectin have been recently reviewed in detail elsewhere, ${ }^{38,48,59)}$ the present discussion will concentrate on glycogen rather than on amylopectin.

Amylopectin. It is now generally accepted that amylopectin has a cluster-type structure. This concept arose independently in the laboratories of $\mathrm{Z}$. Nikuni ${ }^{54)}$ and D. French, ${ }^{55)}$ both of whom have been honoured by this Society. The cluster models (Fig. 2) are in accord with the structural properties of amylopectin, including the relatively high viscosity, partial crystallinity and relative resistance to degradation by acids and enzymes. ${ }^{54-56)}$ Our variant of the model ${ }^{47}$ ) takes account of the $\mathrm{A}: \mathrm{B}$ chain ratio and the change in this ratio when amylopectin is partly debranched with pullulanase. This information was not, of course, available to the previous authors, ${ }^{54-56)}$ and leads to the view that some B-chains carry more than one Achain. A later refinement of the cluster model has been proposed by Hizukuri ${ }^{60)}$ on the basis of a polymodal chain profile. Most clusters consist of A-chains and relatively short Bchains, but some B-chains can extend into two, three or possibly even four clusters. This represents a more quantitative aspect to the varying lengths of the B-chains than is shown qualitatively in the previous diagrams (Fig. 2).

The detailed arrangement of amylose and amylopectin molecules within a starch granule is the subject of continuing speculation, and represents a major problem for future investigations.

Glycogen. Enzymic degradation studies carried out by Meyer and Fuld ${ }^{57)}$ and by Larner and coworkers ${ }^{50}$ led to the postulation of a multiply branched "tree" or bush-like structure for glycogen. The latter group suggested that the branch points were arranged in tiers, which could be detected during a stepwise degradation using muscle phosphorylase and amylo-1,6-glucosidase. Since glycogen molecules have a high molecular weight $\left(\sim 10^{7}\right)$, the number of tiers could be considerable. Madsen and Cori ${ }^{61)}$ have calculated that in a glycogen with a molecular weight of $20 \times 10^{6}$, there would be about 13 successive tiers of branch points, and 50\% of the branch points would be in the outermost tier. Confirmation of this was reported by Misaki and $\mathrm{Yano}^{62)}$ who degraded oyster glycogen by 15 successive treatments with pullulanase.

In 1968, amylopectin was shown ${ }^{63)}$ as a regularly rebranched structure, and in 1970, the same diagram (see Fig. 1d) was used to describe glycogen. ${ }^{51)}$ However, it was not clear why regularity was introduced into the model, since there was ample evidence from the literature that the branch points in these polysaccharides were irregularly distributed $e . g$., the isolation $\alpha$-dextrins containing more than one branch point, ${ }^{64)}$ and the presence of regions which were resistant to $\alpha$-amylase giving rise to macrodextrins. ${ }^{65)}$

This regularly rebranched model for amylopectin and glycogen was revised in 1970 by Whelan and his coworkers ${ }^{51}$ following the enzymic analysis of the corresponding $\phi, \beta$ dextrins i.e., the phosphorylase limit dextrin degraded by $\beta$-amylase. It was believed ${ }^{66)}$ that bacterial isoamylase could not hydrolyse maltosyl side chains. Hence, a $\phi, \beta$-dextrin based on a Meyer structure after treatment with isoamylase, should be resistant to $\beta$-amylase. In fact, the $\phi, \beta$-dextrins from shellfish glycogen and waxy maize amylopectin had $\beta$-amylolysis limits of 44 and $29 \%$, respectively. From this and other results, the structure shown in Fig. le was proposed. In this model, half of the B-chains carried an average of 2A-chains, whilst the other B-chains each carried 2Bchains. However, isoamylase also released a significant amount of maltotriose; this fact was not mentioned by the authors. If, owing to incomplete phosphorolysis, the $\phi$-dextrin contained some maltopentaosyl A-chains (rather than maltotetraosyl A-chains), these would be 


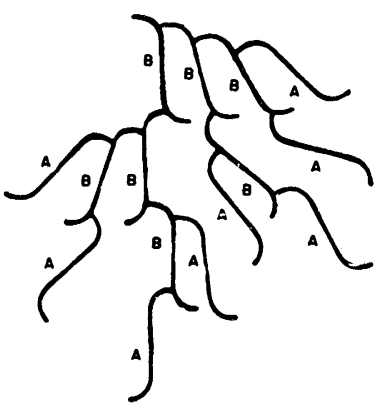

(a)

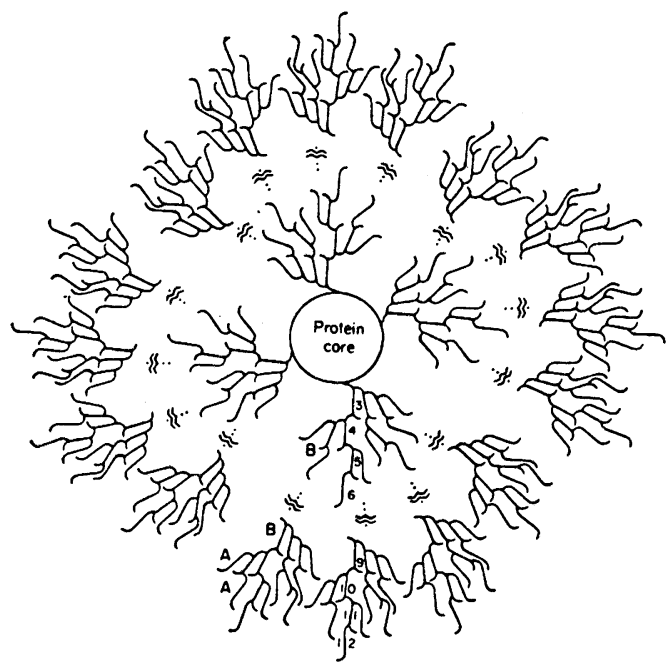

(b)

Fig. 3. Schematic diagram of glycogen.

(a) Relationship between chains in the Whelan model for four tiers of the structure, (b) putative protein core with inner and outer tiers of branch points. From Goldsmith et al. ${ }^{58)}$

converted into maltotriosyl A-chains on $\beta$-amylolysis, and could then be hydrolysed by isoamylase with the release of maltotriose. The resultant polysaccharide would then be susceptible to $\beta$-amylase. Moreover, the specificity of isoamylase is not quite as precise as originally suggested, ${ }^{66)}$ since maltosyl side chains are also slowly hydrolysed. ${ }^{67}$ ) It follows that the revised Meyer structure for glycogen may not be entirely accurate.

A related structure for glycogen based on the above model, with several tiers of branch points, and a protein core, was proposed by Goldsmith and coworkers ${ }^{58}$ (Fig. 3). This structure is based, in part, on two assumptions; firstly, that the individual chains in glycogen are of a fairly uniform length (11-14 glucose residues) and secondly that the A-chains are much longer than the exterior portions of the B-chains. Unfortunately, neither of these assumptions is true. The chain profile of glycogen covers a wide range of chain lengths from six to about 50 glucose. residues. ${ }^{51,68)}$. In addition, there is no evidence to support the presence of two different lengths of exterior chain. In the case of three shellfish glycogens, the lengths of the A-chains as determined by pullulanase degradation were in accord with the calculated values, with c. $1.3,4,6$ and 7 predominating. ${ }^{69)}$

A typical glycogen molecule has a c. 1 . of 13 and a $\beta$-amylolysis limit of $45 \%$; the exterior and interior chain lengths are 8 and 4 , respectively. Since there are equal numbers of exterior and interior chains, and assuming an $\mathrm{A}$ : $B$ chain ratio of $1: 1$, each $B$-chain, on the average, will consist of one exterior and two interior chains. The average lengths of the $\mathrm{A}$ and B-chains are therefore 8 and 18, respectively. The smallest B-chain, consisting of a single exterior and interior chain, would contain 13 glucose residues. Longer B-chains could contain three, four or more interior chains, but the proportion of long B-chains would decrease as their chain lengths increased. A B-chain with four interior chains would contain about 28 glucose residues. During a study of the isoamylolysis of oyster glycogen, the d.p. of the maltosaccharide products increased as a direct function of the degree of debranching. ${ }^{70}$ The chain length of the residual polysaccharide also apparently increased as debranching proceeded. The results were entirely compatible with a spherical Meyer-type structure.

At the present time, it seems that for glycogen, a Meyer-type structure is in accord with majority of the experimental facts. One apparent exception is the pattern of degradation of glycogen by hot alkali, which has been used by Geddes ${ }^{71}$ to support the Whelan revision of the Meyer-structure. However, the detailed mechanism of the alkaline degradation of a branched high molecular weight $(1 \rightarrow 4) \alpha$-Dglucan is not clear. In glycogen, there are more B-chains than A-chains (p. 317). This 
suggests that the proportion of B-chains carrying more than one A-chain is lower than in amylopectin.

The eventual solution of the problem requires further information on the biosynthesis of glycogen. Does glycogen synthase have the same affinity for A and B-chains in a polysaccharide? When an A or B-chain has been lengthened, does branching enzyme show any preference for a particular type of chain? During the action of branching enzyme, is there any preference for intra-chain transfer as against inter-chain transfer ? How does the protein primer for glycogen synthesis (glycogenin) ${ }^{72)}$ interact with glycogen synthase and branching enzyme? The answers to these and related questions are required before the fine structure of glycogen is finally established.

An important difference between amylopectin and glycogen is the tendency of the latter to aggregate with the formation of very high molecular weight $\alpha$-particles. The nature of the "quaternary" structure has been the subject of considerable speculation. In 1962, Drochmans ${ }^{73)}$ isolated particulate glycogen from rat liver by differential centrifugation. These particles were complex and had a diameter of $60-200 \mathrm{~nm}$. Within these complexes, smaller $\beta$-particles 20 $30 \mathrm{~nm}$ in diameter could be recognized by electron microscopy. These $\beta$-particles could also be prepared by treating $\alpha$-particles with different acids at about $\mathrm{pH}$ 3.0. Drochmans also described $^{73)}$ subunits of the $\beta$-particles, termed $\gamma$-elements, which were filaments or rods $3 \mathrm{~nm}$ in diameter and $20 \mathrm{~nm}$ in length. This observation does not appear to have been mentioned in other reviews on glycogen, and requires verification, since the shape of the $\gamma$-elements does not correlate easily with possible molecular models.

Investigations of the nature of the aggregation of the $\beta$-particles have given conflicting results. Geddes and coworkers ${ }^{7 \text { ) }}$ have suggested that $\beta$-particles are synthesised on a protein backbone and that covalent cross-linking by disulphide bonds and perhaps other linkages are involved. A key observation was that the $\alpha$ particles were disaggregated by 2 -mercaptoethanol, as judged by sedimentation studies. However, Hata and coworkers reported ${ }^{75)}$ that the size and shape of $\alpha$-particles, as examined by electron microscopy, was not affected by 2 -mercaptoethanol. The $\alpha$-particles could be disaggregated by a brief treatment with $\alpha$-amylase, suggesting that the $\beta$-particles were linked together by $(1 \rightarrow 4)-\alpha$-D-glucan chains. Nevertheless, neither these chains nor the protein backbone proposed by Geddes would be as labile at $\mathrm{pH} 3.0$ as the experiments of Drochmans had indicated. It may be that the very small proportion of phosphate groups present in some samples of glycogen could form an intermolecular bridge either as a phosphodiester linkage or with a suitable divalent metal ion, although this would require the presence of phosphate groups on the periphery of the glycogen molecules, and some regularity in their distribution.

It is clear that the relationship between the $\alpha$ - and $\beta$-particles of glycogen remains a major problem for future research.

\section{CONCLUSION AND ACKNOWLEDGEMENTS}

This review has been a rather personal account of 40 years of research on starch and glycogen. During this period, progress has been greatly facilitated by the availability of debranching enzymes, whose use has provided information unobtainable by other methods of analysis. Nevertheless, numerous problems remain for investigation and future developments will be awaited with great interest.

Our own work has been partly based on that carried out by starch and glycogen biochemists in other laboratories, several of whom have already been honoured by this Society. It is a great privilege to be associated with them on this occasion. It is regretted that limitations of time and space have prevented the presentation of a more detailed account of their work.

I wish to record my indebtedness to my many collaborators whose careful experimental work is recorded in the bibliography, to my mentors, the late Dr. D. J. Bell and the late Sir Edmund Hirst, who first aroused and then encouraged my interest in glycogen and starch, and to Suntory Limited for their support and cooperation during the last two decades. 


\section{REFERENCES}

1) For a review, see D. J. BELl : Biol. Revs., 23, 256-266 (1948).

2) W. N. HAWORTH and E. G. V. Percival : $J$. Chem. Soc., 2277-2282 (1932).

3) D. J. BELL : Biochem. J., 29, 2031-2035 (1935).

4) W. N. HAWORTH, E. L. HIRST and F. A. ISHERWOOD : J. Chem. Soc., 577-581 (1937).

5) S. NishimURA : Nippon Nogei-Kagaku Kaishi, 6, 160-167 (1930) ; T. MiNAGAWA : Nippon Nogei-Kagaku Kaishi, 8, 176-183 (1932).

6) B. MARUO and T. KoBAYASHI : Nature, 167, 606-607 (1951).

7) D. J. Bell : J. Chem. Soc., 992-996 (1948).

8) M. AbDel-AKher, J. K. Hamilton, R. MontGOMERY and F. SMith : J. Am. Chem. Soc., 74, 4970-4971 (1952).

9) M. L. Wolfrom and A. Thompson : J. Am. Chem. Soc., 79, 4212-4215 (1957).

10) M. L. Wolfrom and A. Thompson: $J . A m$. Chem. Soc., 78, 4116-4117 (1956).

11) O. P. BAHL and F. SMith : J. Org. Chem., 31, 2915-2920 (1966).

12) J. K. Hamilton and F. Smith : J Am. Chem. Soc., 78, 5910-5912 (1956).

13) M. ABDEl-AKher and F. SMith : Arch. Biochem. Biophys., 78, 451-459 (1958).

14) D. J. MANners and G. A. Mercer : J. Chem. Soc., 4317-4322 (1963).

15) D. J. Bell and D. J. Manners : J. Chem. Soc., 1891-1893 (1954).

16) A. Thompson, K. ANNo, M. L. Wolfrom and M. INATOMe : $J$. Am. Chem. Soc., 76, 1309-1311 (1954).

17) D. J. Manners, G. A. Mercer and J. J. M. Rowe : J. Chem. Soc., 2150-2156 (1965).

18) V. C. BARRY, T. G. HAlsall, E. L. HiRST and J. K. N. JONES : J. Chem. Soc., 1468-1470 (1949).

19) I. D. Fleming, E. L. HIRST and D. J. MANNERS: J. Chem. Soc., 2831-2836 (1956).

20) For a review of Floridean Starch, see D. J. MANNERS and R. J. STURGEON : in Encyclopedia of Plant Physiology, New Series, Vol. 13A, Plant Carbohydrates I, Intracellular Carbohydrates, F. A. LoEWUS and W. TANNER, eds., SpringerVerlag, Berlin, pp. 475-478 (1982).

21) P. M. BRUNSWICK and D. J. MANNERS : Biochem. Soc. Trans., 9 (2), 290P (1981).

22) C. T. Greenwood and J. THOMSON : J. Chem. Soc., 1534-1537 (1961).

23) S. Peat, J. R. Turvey and J. M. Evans : $J$. Chem. Soc., 3223-3227 (1959).

24) S. Peat, J. R. Turvey and J. M. Evans : $J$.
Chem. Soc., 3341-3344 (1959).

25) S. Peat, S. J. Pirt and W. J. Whelan : $J$. Chem. Soc., 705-713, 714-722 (1952).

26) J. M. G. Cowie, I. D. Fleming, C. T. GREENWOOD and D. J. MANNERS : J.Chem.Soc., 44304437 (1957).

27) S. Peat, G. J. Thomas and W. J. Whelan : $J$. Chem. Soc., 722-733 (1952).

28) W. BANKS, C. T. GREENWOOD and I. G. JONES : J. Chem. Soc., 150-155 (1960).

29) W. L. Cunningham, D. J. Manners, A. Wright and I. D. Fleming: J. Chem. Soc., 2602-2613 (1960).

30) H. Baum, G. A. Gilbert and N. D. Scott : Nature, 177, 889-890 (1956).

31) W. BANKS and C. T. GREENWOOD : Chem. Ind., 714-715 (1961).

32) O. KJOLBERG and D. J. MANNERS : Biochem. J., 86, 258-262 (1963).

33) P. N. Hobson, W. J. Whelan and S. PEAT : $J$. Chem. Soc., 1451-1459 (1951).

34) Z. H. GUNJA, D. J. MANNERS and KHIN MAUNG: Biochem. J., 81, 392-398 (1961).

35) W. BANKS and C. T. GreENWOOD : Stärke, 19, 197-206 (1967).

36) Y. TAKEDA, K. SHIRASAKA and S. HIZUKURI : Carbohydr. Res., 132, 83-92 (1984).

37) A. MISAKI and F. SMITH : Carbohydr. Res., 4, 109-114 (1967).

38) For a review see D. J. MANNERS : In Biochemistry of Storage Carbohydrates in Green Plants, P. M. DEY and R. A. DIXON, eds., Academic Press, London, pp. 149-203 (1985).

39) S. HizuKuri, K. Shirasaka and B. O. Juliano: Stärke, 35, 348-350 (1983) ; Y. TAKEDA, S. HIZUKURI and B. O. JUliano : Carbohydr. Res., 148, 299-308 (1986).

40) S. HizUKURI, Y. TAKEDA, M. YASUdA and A. SUZUKI : Carbohydr. Res., 94, 205-213 (1981); Y. TAKEDA, S. HIZUKURI, C. TAKEDA and A. SUZUKI : Carbohydr. Res., 165, 139-145 (1987).

41) S. Peat, W. J. Whelan and G. J. Thomas : $J$. Chem. Soc., 4546-4548 (1952).

42) S. Peat, W. J. Whelan and G. J. Thomas : $J$. Chem. Soc., 3025-3030 (1956).

43) B. S. ENEVoldSEN and D. J. MANNERS : Methods Carbohydr. Chem., 11, in press (1990).

44) B. S. ENEVoldSEN and B. O. Juliano : Cereal. Chem., 65, 424-427 (1988).

45) G. N. BAthgATE and D. J. MANNERS : Biochem. $J .$, 101, 3C-5C (1966).

46) J. J. Marshall and W. J. Whelan : Arch. Biochem. Biophys., 161, 234-238 (1974).

47) D. J. MANNERS and N. K. MATHESON : Carbohydr. Res., 90, 99-110 (1981). 
48) D. J. Manners : Carbohydr. Polym., 11, 87-112 (1989).

49) K. UmeKi and T. Yamamoto: Agric. Biol. Chem., 41, 1515-1517 (1977).

50) J. LARNer, B. ILlingWORTH, G. T. CORI and C. F. CORI : J. Biol. Chem., 199, 641-651(1952).

51) Z. Gunja-Smith, J. J. Marshall, C. Mercier, E. E. SMITH and W. J. WhELAN : FEBS Lett., 12, 101-104 (1970).

52) D. Borovsky, E. E. SMith, W. J. Whelan, D. FRENCH and S. KIKUMOTO: Arch. Biochem. Biophys., 198, 627-631 (1979).

53) K. H. MeYer and P. Bernfeld : Helv. Chim. Acta, 23, 875-885 (1940).

54) For a review see Z. NiKUNI : Denpun Kagaku, 22, 78-92 (1975).

55) D. FreNCH : Denpun Kagaku, 19, 8-25 (1972).

56) J. P. Robin, C. Mercier, R. CharbonNiere and A. Guilbot : Cereal Chem., 51, 389-406 (1974).

57) K. H. MeYer and M. Fuld : Helv. Chim. Acta, 24, 375-378 (1941).

58) E. GoldSMiTh, S. SPRANG and R. FletTERICK: J. Mol. Biol., 156, 411-427 (1982).

59) D. J. MANNERS : Cereal Foods World, 30, 461467 (1985).

60) S. HizUKuRI : Carbohydr. Res., 147, 342-347 (1986).

61) N. B. MAdSEN and C. F. CoRI : J. Biol. Chem., 233, 1251-1256 (1958).

62) A. MISAKI and M. YANO : Biryoeiyouso Kenkyu (Journal of Trace Nutritional Elements Research), 2, 161-168 (1985).
63) E. Y. C. LEE, C. MERCIER and W. J. WHELAN : Arch. Biochem. Biophys., 125, 1028-1030 (1968).

64) P. J. P. RoBERTS and W. J. WhELAN : Biochem. $J .$, 76, 246-253 (1960).

65) G. L. BRAMMER, M. A. ROUgViE and D. FRENCH: Carbohydr. Res., 24, 343-354 (1972).

66) Z. Gunja-Smith, J. J. Marshall, E. E. SMITH and W. J. WhELAN : FEBS Lett., 12, 96-100 (1970).

67) R. M. Evans, D. J. MANneRS and J. R. STARK : Carbohydr. Res., 76, 203-213 (1979).

68) S. A. S. CRaig, A. M. L. McDonald, D. J. MANNERS and J. R. STARK : Carbohydr. Res., 179, 327-340 (1988).

69) K. Hata, M. hata, M. Hata and K. MatsuDA : Denpun Kagaku, 30, 95-101 (1983).

70) T. N. PAlMeR, L. E. MACASKIE and K. K. GREWAL : Carbohydr. Res., 115, 139-150 (1983).

71) H. M. BullivanT, R. GedDES and P. R. Wills: Biochem. Int., 6, 497-506 (1983).

72) J. LOMAKO and W. J. WHELAN : BioFactors, 1, 261-264 (1988).

73) P. Drochmans : J. Ultrastruct. Res., 6, 141-163 (1962).

74) R. Geddes and G. C. Stratton : Carbohydr. Res., 57, 291-299 (1977) ; R. GedDES, J. D. HARVEY and P. R. WILLS : Eur. J. Biochem., 81, 465-472 (1977).

75) K. Hata, M. Hata, M. Hata and K. Matsuda: Denpun Kagaku, 31, 146-155 (1984).

(Received September 26, 1989) 